\title{
Mirror gazing increases attractiveness in satisfied, but not in dissatisfied women; a model for body dysmorphic disorder?
}

Citation for published version (APA):

Mulkens, S., \& Jansen, A. T. M. (2009). Mirror gazing increases attractiveness in satisfied, but not in dissatisfied women; a model for body dysmorphic disorder? Journal of Behavior Therapy and Experimental Psychiatry, 40(2), 211-218. https://doi.org/10.1016/j.jbtep.2008.10.001

Document status and date:

Published: 01/01/2009

DOI:

10.1016/j.jbtep.2008.10.001

Document Version:

Publisher's PDF, also known as Version of record

Document license:

Taverne

Please check the document version of this publication:

- A submitted manuscript is the version of the article upon submission and before peer-review. There can be important differences between the submitted version and the official published version of record.

People interested in the research are advised to contact the author for the final version of the publication, or visit the DOI to the publisher's website.

- The final author version and the galley proof are versions of the publication after peer review.

- The final published version features the final layout of the paper including the volume, issue and page numbers.

Link to publication

\footnotetext{
General rights rights.

- You may freely distribute the URL identifying the publication in the public portal. please follow below link for the End User Agreement:

www.umlib.nl/taverne-license

Take down policy

If you believe that this document breaches copyright please contact us at:

repository@maastrichtuniversity.nl

providing details and we will investigate your claim.
}

Copyright and moral rights for the publications made accessible in the public portal are retained by the authors and/or other copyright owners and it is a condition of accessing publications that users recognise and abide by the legal requirements associated with these

- Users may download and print one copy of any publication from the public portal for the purpose of private study or research.

- You may not further distribute the material or use it for any profit-making activity or commercial gain

If the publication is distributed under the terms of Article $25 \mathrm{fa}$ of the Dutch Copyright Act, indicated by the "Taverne" license above, 


\title{
Mirror gazing increases attractiveness in satisfied, but not in dissatisfied women: A model for body dysmorphic disorder?
}

\author{
Sandra Mulkens*, Anita Jansen \\ Department of Clinical Psychological Science, Maastricht University, Faculty of Psychology and Neuroscience, P.O. Box 616, \\ 6200 MD Maastricht, The Netherlands
}

\section{A R T I C L E I N F O}

Article history:

Received 22 June 2006

Received in revised form

30 September 2008

Accepted 1 October 2008

\section{Keywords:}

BDD

Body dysmorphic disorder

Mirror gazing

Self-focused attention

Body image

\begin{abstract}
A B S T R A C T
Body dysmorphic disorder is a severe disturbance in which the person is preoccupied with an imagined defect in appearance. It is unclear what causes and what maintains BDD, although it is assumed that patients are characterized by an increased selffocused attention. Since patients spend a lot of time examining their 'defect' in reflecting surfaces, it might well be that mirror gazing itself is an important maintaining factor for BDD, as it may lead to a loss of sense of proportions. If so, normal individuals' body evaluations are expected to decrease likewise after mirror exposure. In the present study, 50 female students watched both their own face in the mirror and a photograph of a neutral female face for $3.5 \mathrm{~min}$. Before and after gazing, they rated the attractiveness of the faces. Results indicate that mirror exposure did not lead to decreased attractiveness in normal participants. However, when participants were divided into high and low satisfaction about appearance, highly satisfied individuals' evaluations of their own face improved, whereas low satisfied individuals' evaluations tended to decrease. For the other face, only the low satisfied individuals showed increased attractiveness scores at post-test. The results are explained by selective visual attention and are in line with recent findings in eating disordered women.
\end{abstract}

(c) 2008 Elsevier Ltd. All rights reserved.

\footnotetext{
* Corresponding author. Tel.: +31 43388 4052; fax: +31 433884196.

E-mail address: s.mulkens@psychology.unimaas.nl (S. Mulkens).
} 


\section{Introduction}

Body dysmorphic disorder (BDD) can be a chronic, debilitating condition in which the person is preoccupied with an imagined defect in one's appearance or, in the case of a slight physical anomaly, the person's concern is markedly excessive (American Psychiatric Association, 2000). The concerns often relate to one or more body parts that are visible to other people, such as the nose, ears, skin and eyes. However, the preoccupations might also concern the more covered body parts such as the muscles or genitals (Albertini \& Phillips, 1999). Reliable data on the prevalence of BDD are still lacking, but it seems to affect men and women equally and it usually develops around adolescence (Phillips, Kim, \& Hudson, 1995). BDD patients spend a lot of time - about 3-8 h per day (Phillips, 1996) - thinking about their defect, examining it in mirrors or other reflecting surfaces, and trying to hide, camouflage or even change the so-called deformity (Veale, 2000; Veale \& Riley, 2001). The disorder is, thus, time consuming and chronic, although the level of functioning may vary across individuals: some people function reasonably well while others are isolated, develop a (secondary) depression or even commit suicide (Cororve \& Gleaves, 2001).

It is yet unclear what causes and what maintains BDD. It is suggested that its maintaining factors are cognitive, affective and behavioural in nature (Veale, 2004; Veale et al., 1996; Veale \& Riley, 2001). Regarding the cognitive part, BDD patients are assumed to be characterized by an increased selffocused attention (SFA), as is seen in social phobic patients (Clark \& Wells, 1995; Rapee \& Heimberg, 1997). Several theories argue that attention can either be focused externally, e.g., to the world around or the task at hand, or internally, to aspects of the self, like thoughts and feelings. The latter produces a heightened SFA (Buss, 1980; Carver \& Scheier, 1983; Duval \& Wicklund, 1972). According to Rapee and Heimberg (1997), social phobics tend to have a more negative mental representation of their external appearance. Increasing SFA will enhance awareness to this negative mental representation, thus producing anxiety. Clark and Wells (1995) proposed that because people with social phobia are excessively self-aware, they do not process positive social feedback. As a result, they rely on their own negative evaluations to assess their social performance. Based on these theoretical models, there should be an interaction between negative evaluation or negative mental representation and self-focus in producing social anxiety (Zou, Hudson, \& Rapee, 2007).

Self-focused attention in BDD is characterized by excessive focusing towards the own body, instead of dealing with external information (Veale et al., 1996). This process of selective attention appears to be focused on specific features of an image leading to a heightened awareness and relative magnification of certain aspects, which contributes to the development of a distorted body image (Veale, 2004). Thus, frequent mirror gazing at the 'disfigured' body part, might lead to distorted, or enlarged, images. Through intense and prolonged inspection of the "ugly" part, BDD patients might lose their sense of proportions (Veale \& Riley, 2001). In a recent study on visual attention processes (by means of eye movements recordings), Grocholewski, Heinrichs, and Lingnau (2007) proved that candidate patients for cosmetic surgery who could be diagnosed as BDD ( $n=4$ patients out of 15 candidate patients) indeed demonstrated a specific attentional focus on 'ugly' facial areas.

Situational SFA may be induced by the presence of an audience, a mirror or a video camera (Buss, 1980). Frequent and prolonged mirror gazing implies an increased self-focused attention. Note that mirror gazing is one of the most remarkable characteristics of BDD patients. Therefore, it might be hypothesized that mirror gazing acts as an important maintaining factor for BDD.

If mirror gazing by itself is indeed an important determinant for a negative evaluation of parts of one's appearance, it might be expected that normal individuals' evaluation of (parts of) their bodies would decrease likewise after sustained mirror exposure. That is, inducing a state of self-focused attention by gazing at the face for a while, might lead to an unfavourable impression in undisturbed individuals, as well. Research by Hofmann and Heinrichs (2002) indicated that undisturbed individuals with prior mirror exposure indeed reported more statements about their bodily appearance than undisturbed individuals without this prior mirror exposure. However, there was a balance between the amount of positive and negative statements reported. This might be explained by the fact that individuals were asked to record three positive and three negative characteristics about themselves. To investigate what would happen in a more naturalistic situation of mirror gazing (that is, without specific directions on the amount of positive or negative answers) we had undisturbed individuals - in 
this case psychology students - undergo a self-focused attention manipulation and investigated its consequences on attractiveness ratings. Undergraduate students are often used as representatives of the normal population since it is relatively easy to find enough individuals who are willing to participate. Although students may represent a specific subgroup from the general population (with respect to age and intelligence), the sample is not likely to differ in a substantial way from the general adolescent population and from adolescents with body image problems. That is, body image disorders such as BDD usually start in adolescence and probably occur in all levels of the population. In the present study, 50 female students watched both their own face in the mirror and a photograph of a neutral female face for $3.5 \mathrm{~min}$. Before and after gazing, they rated the attractiveness of the faces. It was hypothesized that individuals would rate a face less attractive after $3.5 \mathrm{~min}$ of gazing, compared to before. Furthermore, we expected this to be more pronounced when their own face was the subject of gazing. Finally, by creating extreme groups with regard to body dissatisfaction within the sample, we sought to study whether our hypothesis would be confirmed in analogue groups.

\section{Method}

\subsection{Participants}

Participants were 50 female, Caucasian undergraduate psychology students. Mean age was 20.9 (SD 1.99; range 18-30) and all students were unmarried. They were recruited by registration forms that were distributed during lectures.

\subsection{Stimulus materials}

The stimulus materials consisted of the participant's own face in a mirror, and a color photograph of a neutral-looking young woman. The photograph was taken from a website of a professional photographer and was chosen after a small pilot study in which five panel members judged 20 female faces with respect to 'normality of looks' (that is, absence of unusual/deviant characteristics that leap to the eye) and neutrality of expression. Furthermore, the photograph fitted within the age and ethnic group of our participants. The photograph was enlarged to a size that corresponded with the size of their own face in the mirror. A rectangular mirror, 15 by $20 \mathrm{~cm}$, was used for gazing. Both conditions differed in the sense that in the mirror condition participants looked at their moving mirror image, whereas in the picture condition looked at a still photo from its normal perspective. The participant sat on a chair at a table on which the mirror was placed at $50 \mathrm{~cm}$ from the tableside. The wall behind the participants was empty, so that no distractors were present. A white cardboard was used to cover the mirror in between exposures.

\subsection{Procedure}

The participant was welcomed to the laboratory and asked to seat herself on the chair at the table on which the - covered - mirror was placed. The chair was adjustable in height. Then, the participant was informed that the study was concerned with symmetry and appearance, about which some questionnaires had to be filled out.

The mirror exposure to their own face and the display of the photograph were counterbalanced across subjects. The participant was shown the first stimulus (face or photograph) for $5 \mathrm{~s}$. Then, the mirror was covered or the photograph was turned over and the first set of VASs was answered (premeasure of symmetry and attractiveness). Then, the individual was instructed to examine her own face or the photograph again in a concentrated way. She was asked to sit straight and look into the mirror or at the photograph constantly, without turning away, and with the same - neutral - expression throughout. No instructions were given about the way of looking or about the location that should be looked at. Participants were just told to look in a concentrated way at their face or at the photograph. This exposure period lasted for $3.5 \mathrm{~min}$, whereafter the VASs were completed again (post-measure). The whole procedure was repeated for the other stimulus (face or photograph). Finally, the participant filled out a questionnaire that interrogated BDD symptoms. The exposure period of $3.5 \mathrm{~min}$ was chosen 
on the basis of a pilot, carried out by five students who were involved in the data acquisition. A time period was sought in which the individual would have enough time to scrutinize her face/the photograph, but not so much time that she would become bored or would become more easily distracted. A study by Veale and Riley (2001) showed that the mean duration of short mirror gazing sessions in BDD patients was 4.8 min, which is somewhat more. In our pilot, however, 3.5 min seemed quite a lot of time to scrutinize oneself, without doing anything. To check whether the individual indeed kept watching her mirror image or the photograph, the experimenter remained in the room but at a comfortable distance $(3 \mathrm{~m})$, whereas she pretended reading something. Nevertheless, when the experimenter noticed that the individual was not watching herself or the photograph (anymore), she was instructed to redirect her attention to the stimulus and keep scrutinizing. This happened four times, altogether. Of course, the presence of the experimenter might have caused some discomfort in the test individuals since they may have felt more self-conscious. However, since the goal of the study was to bring normal individuals into a condition of self-awareness (what mirror gazing is implying, as well), we feel that this is not a prohibitive objection to the validity of the study. If anything, it seemed more important that the individuals kept watching their mirror image or the photograph than that they would feel too uncomfortable by the presence of the experimenter.

\subsection{Assessment}

Visual Analogue Scales; after each exposure (that is, at pre- and at post-measure), the individual completed 12 Visual Analogue Scales $(100 \mathrm{~mm}$ lines on which the individual puts a vertical line to indicate her opinion) about symmetry and 12 about attractiveness. The following parts of the head were chosen to be judged: the eyes, ears, chin/jaw, hair(cut), facial skin, eyebrows, nose, cheek(bone)s, mouth, lips, teeth and face in general. The left side of the VAS was indicated "0" and "not symmetric at all" or "not attractive at all", respectively, whereas the right end indicated " 100 " and "very symmetric" or "very attractive", respectively. The questions on symmetry were used as filler items, attractiveness ratings were the dependent variables.

My Looks Questionnaire (Bouman, 1999; Bouman, in preparation) is a questionnaire that investigates the extent to which someone is concerned about his appearance and the extent to which one suffers from BDD symptoms. For this study, only the BDD-questions were used, measuring a global dissatisfaction with appearance and consisting of 18 items. Examples of the items are: "I feel sad because of my appearance", "I avoid looking in mirrors". Two items consider the use of medical visits and altering the appearance by cosmetic surgery. The total score ranges from 18 (not symptomatic) to 88 (highly symptomatic). Most of the items can be classified into one of two factors: active and passive avoidance. The internal consistency of the scale is high (alpha $=0.88)$, and it has good discriminant validity. That is, the scale is able to discriminate between BDD patients and the general population $(t(465)=-18.5$, $p<0.001$, means being 62.1 (SD 7.9) and 40.2 (SD 8.7), respectively).

\subsection{Data reduction and analysis}

Mean VAS attractiveness scores were computed for both their own face and the other face, before and after the long exposure. A 2 (time: before versus after) $\times 2$ (face: own face versus other face) ANOVA was conducted on these data. Next, extreme groups were created with respect to body dissatisfaction selecting the individuals whose scores were in the lowest and highest third of "My Looks Questionnaire". We then conducted a 2 (groups: high versus low body satisfaction) $\times 2$ (time: before versus after) $\times 2$ (face: own face versus other face) ANOVA with the attractiveness values as the dependent variable.

\section{Results}

The 2 (time: before versus after) $\times 2$ (face: own face versus other face) ANOVA revealed a significant main effect of Time $(F(1,49)=10.2, p<0.005)$. Inspection of the means indicate that after exposure, overall attractiveness scores were higher than before.

There was also a significant interaction effect of time and face $(F(1,49)=4.6, p<0.05)$. 
Post hoc $t$-tests indicated that the effect was due to increased attractiveness values for the other face $(t(49)=3.1, p<0.005)$, whereas there was no significant increase between pre- and post-attractiveness values for the own face $(t(49)=1.01, p=0.32)$. See also Table 1 .

Mean 'My Looks' scores of the lowest and highest 33\% of the sample were as follows: highly satisfied individuals $(N=16)$ : 34.5 (SD 3.0; range 28-38); low satisfied individuals $(N=16)$ : 51.9 (SD 3.2; range 46-57). After creating extreme groups, the 2 (groups: high versus low satisfaction) $\times 2$ (time: before versus after) $\times 2$ (face: own face versus other face) ANOVA with the attractiveness values as the dependent variable, revealed a significant interaction effect of group, time, and face $(F(1,30)=4.2$, $p<0.05$ ).

Post hoc $t$-tests indicated that high and low satisfied individuals had significantly different attractiveness scores for their own face at post-test $(t(30)=2.5, p<0.05)$. That is, the highly satisfied individuals showed an increased score $(t(15)=-1.9, p=0.035$ (one-tailed)), whereas the mean score of the low satisfied participants tended to decrease $(t(15)=1.5, p=0.083$ (one-tailed)). For the other face, only the low satisfied individuals showed increased attractiveness scores at post-test $(t$ $(15)=-2.4, p<0.05$ ). We computed effect sizes for the group differences separated by conditions (Cohen's $d$ ). The effect size for the condition 'own face' was 0.85 which is large. The effect size for the condition 'other face' was 0.33 which is rather small.

In sum, the high satisfied participants evaluated their own face more positively after mirror exposure, whereas the low satisfied participants tended to lower their scores. Furthermore, only the low satisfied evaluated the other face as more positively after the same amount of exposure to this face.

\section{Discussion}

The hypothesis in this study was that the self-focused attention at the face would result in a more negative evaluation of this face. It was expected that this would be most pronounced after mirror gazing at the own face in contrast to gazing at another face.

The results of this study do not confirm our hypothesis. That is, mirror exposure of $3.5 \mathrm{~min}$ does not lead to decreased ratings of attractiveness in normal participants. Yet, evaluation of the own face remained about the same, whereas the attractiveness of another face even increased after $3.5 \mathrm{~min}$ of looking, resulting in about the same post-values as were indicated for the own face. An explanation for the fact that undisturbed individuals rated the other face more unfavourable - relatively to the own face - in the first instant could be that they display a self-serving bias. That is, when looking at other people, undisturbed individuals might prefer to look at those people's less beautiful body parts, rather than at their most beautiful body parts. The latter suggestion was recently tested and confirmed in a population suffering from body image problems, namely eating disordered patients (Jansen, Nederkoorn, \& Mulkens, 2005). In this study, eating symptomatic (bulimia nervosa) and normal control participants - whose BMI was comparable - were exposed to digitalized pictures of their own body and control bodies, while eye movement registration was used to measure the degree of visual selective attention. The results indicated that high symptomatic participants focused less on their "beautiful" body parts, whereas priority was given to inspection of their "ugly" body parts. In the normal control group, a self-serving bias was found: these individuals focused more on their "beautiful" body parts and less on their "ugly" body parts. When viewing other bodies, this pattern was reversed: eating disordered participants allocated their attention to beautiful parts of other bodies, whereas normal controls focused on the ugly parts of other bodies. The ratings of attractiveness were comparable to the

Table 1

Means (and SDs) of all pre- and post-measures in both conditions and for high and low satisfied individuals.

\begin{tabular}{|c|c|c|c|c|c|c|}
\hline & & \multirow[t]{2}{*}{ My looks Questionnaire } & \multicolumn{2}{|l|}{ Own face } & \multicolumn{2}{|c|}{ Other woman's face } \\
\hline & & & Pre & Post & Pre & Post \\
\hline Whole group & $N=50$ & $\begin{array}{l}42.7(7.6) \\
{ }^{*} n=49\end{array}$ & $53.8(12.2)$ & $54.7(14.1)$ & $50.3(14.8)$ & $54.8(13.9)$ \\
\hline High versus & High satisfaction $(n=16)$ & $34.5(3.0)$ & $55.2(9.3)$ & $58.2(13.1)$ & $52.5(14.1)$ & $54.8(14.4)$ \\
\hline low satisfaction & Low satisfaction $(n=16)$ & $51.9(3.2)$ & $50.5(9.3)$ & $48.6(7.9)$ & $51.5(10.3)$ & $56.4(10.2)$ \\
\hline
\end{tabular}


attractiveness ratings of the own face after 3.5 min gazing; this might be explained as a consequence of mere exposure.

However, when individuals were divided into low and high concerned about bodily appearance, a very different pattern was revealed, tending to confirm our hypothesis. It appeared that the highly satisfied individuals (i.e., the low BDD symptomatics) evaluated their own face in a positive way at post-test, whereas the least satisfied individuals (i.e., the high BDD symptomatics) rather inclined to a decrease in attractiveness ratings of their own face. Conversely, with respect to the other face, the most dissatisfied participants showed the largest increase in post-attractiveness scores. What does this mean? Relating the data to a model for BDD, it might be concluded that low satisfied individuals seem to be more troubled by mirror gazing, resulting in a decline in attractiveness evaluations. Undisturbed individuals, however, are not bothered at all, or even obtain a more positive image after gazing. What then, would drive BDD patients to keep looking in the mirror? In other words, what is the reinforcing mechanism behind this? Veale and Riley (2001) investigated the psychopathology of mirror gazing by using a self-report questionnaire about mirror gazing among BDD patients and normal controls. They concluded that mirror gazing in BDD consists of a series of complex safety behaviours and that it does not follow a simple model of anxiety reduction that occurs in, for instance, the compulsive checking of obsessive-compulsive disorder. They found that, prior to gazing, BDD patients are driven by the hope that they will look different; the desire to know exactly how they look; a belief that they will feel worse if they resist gazing and the desire to camouflage themselves. BDD patients invariably felt worse after mirror gazing and were more likely to use ambiguous surfaces such as the backs of CDs or cutlery for a reflection.

It remains, as yet, unclear how mirror gazing would lead highly symptomatic individuals to judge themselves as less attractive. Apparently it is not just looking, mere exposure to the whole face, which results in distorted images. It might well be due to the specific visual strategy used by high and low concerned individuals when gazing at their reflections. That is, highly symptomatic individuals might display a greater selective attention for their perceived facial flaws, whereas low symptomatic individuals might display more attention to their presumed beautiful facial parts or to the face as a whole. See also the above-mentioned study (Jansen et al., 2005) which is in line with these suggestions. It might, thus, well be that the undisturbed group in the present study also displays a self-serving bias for beautiful facial parts, whereas the low satisfied group does not. Still, future research with eye movement registration is needed to confirm this hypothesis in BDD patients. Also, it is interesting to see whether undisturbed individuals allocate their attention more to the whole face as opposed to only beautiful facial parts. Furthermore, only the low satisfied individuals evaluated the other face as significantly more positive after the same amount of exposure to this face. This also fits into the model that BDD patients do not find themselves attractive but more easily think that other people are. Evaluating the appearance of others more positively in contrast to one's own appearance could lead to poor self-evaluation, thus reinforcing body dissatisfaction and contributing toward the maintenance of the disorder, as was also found in a study with eating disorders by Legenbauer, Kleinstauber, Muller, and Stangier (2008). These authors found that normal controls were significantly more accurate than individuals with an eating disorder at detecting flaws in other people's bodies and more easily detected the degree of manipulation of several photographs.

Limitations of this study relate to the generalization of the findings to BDD patients, as in this study only students participated, who were exclusively female. However, since the low satisfied students scored substantially higher than the general population on a BDD questionnaire, they might be viewed as a sub-clinical group. The high satisfied group, on the other hand, scored considerably lower than the general population. Thus, at least we were successful in creating extreme concern groups. The fact that only females participated might not be so bad, since BDD seems to be equally divided among men and women (Rosen, 1995). Also, it has been documented that women in the general population are most often dissatisfied with their hair, skin and breasts, while men focus mostly on their hair, nose and ears (Rief, Buhlmann, Wilhelm, Borkenhagen, \& Brähler, 2006). Among BDD patients, Phillips and Diaz (1997) found that women and men's preoccupations only differed with respect to weight, hips (more women), body build, and genitals (more male patients). Thus, watching the face in a mirror still covers most body parts that both men and women are concerned about. Of course, this does not automatically imply that the same mechanism accounts for the finding in both men and women but there seems to 
be neither reason at this moment to assume that these mechanisms would be different. Future research may address this question. Still, it might be that the scores on the BDD questionnaire were influenced by the experiment. Administering the questionnaire any earlier, however, might have influenced the experiment, as the participants may have been prompted by the questions to scrutinize a specific part of their face. Furthermore, it is not clear whether a low mood may be responsible for the findings. That is, participants with low mood may view their appearance as more negative and may lack a self-serving bias. Still, it may well be that low mood and a lack of self-serving bias are secondary BDD symptoms, as we know from the literature that BDD patients often suffer from comorbid depressive symptomatology (Nierenberg et al., 2002; Phillips, 1999). Classifying groups according to their BDD symptomatology seems, at first, thus, a justified strategy for investigating the hypotheses. The use of a real face in the mirror versus a perfectly motionless picture might be a potential confound in this study. That is, it might be that individuals have changed their expressions while gazing, whereas it was not possible to change the expressions of the photograph. For testing the consequences of mirror gazing in BDD, it is important to mimic a realistic situation. We tried to minimize this by instructing participants to sit still and look in the mirror in a neutral, steady way. Also, the face and the picture were of equal size. However, future studies might experiment with gazing at another person's face in the mirror as a control condition (instead of gazing at a still photograph) or with gazing at the individual's own face on a picture. Finally, the actual changes in attractiveness ratings are rather small, although statistically significant. It might, however, well be that real BDD patients show greater pre- and post-changes. Furthermore, the fact that the high and low dissatisfied individuals tend to react oppositely is an interesting finding to further investigate.

In conclusion, given the present results, mirror gazing might well be an important maintaining factor for BDD in that it leads to a less positive self-image in a vulnerable sample. When it would appear that the kind of visual strategy is responsible for the decreased attractiveness scores, this could be further used in treatment. That is, BDD patients could be trained to focus their attention more externally, to the task at hand, instead of focusing their attention towards their perceived flaws. A helpful strategy to do this is called Task Concentration Training (TCT) which was already successfully applied in individuals with social phobia and fear of blushing (e.g., Mulkens, Bögels, \& De Jong, 1999; Mulkens, Bögels, De Jong, \& Louwers, 2001). Within TCT, mirror retraining is a helpful strategy for retraining one's attention to the whole face instead of to 'flaws' only (see also e.g., Grant \& Phillips, 2005).

\section{Acknowledgements}

The authors like to thank Eveline de Groot, Harm Hamers, Elke Jansen, Christine Kerzel, Lin Kleiweg and Tim Philips for their help with the data acquisition and Theo Bouman for providing his "My Looks Questionnaire" and its psychometric properties.

\section{References}

Albertini, R. S., \& Phillips, K. A. (1999). Thirty-three cases of body dysmorphic disorder in children and adolescents. Journal of the American Academy of Child and Adolescent Psychiatry, 38, 453-459.

American Psychiatric Association. (2000). Diagnostic and statistical manual of mental disorders (4th ed., Text Revision). Washington DC: American Psychiatric Association.

Bouman, T. K. (1999). Mijn Uiterlijk Vragenlijst. Rijksuniversiteit Groningen.

Bouman, T.K. Measuring body dissatisfaction in BDD patients and non-clinical samples, in preparation.

Buss, A. H. (1980). Self-consciousness and social anxiety. San Francisco: W.H. Freeman.

Carver, M. F., \& Scheier, C. S. (1983). Self-directed attention and the comparison of self with standards. Journal of Experimental Social Psychology, 19, 205-222.

Clark, D. M., \& Wells, A. (1995). A cognitive model of social phobia. In R. G. Heimberg, M. R. Liebowitz, D. A. Hope, \& F. R. Schneier (Eds.), Social phobia: Diagnosis, assessment, and treatment. New York/London: The Guilford Press.

Cororve, M. B., \& Gleaves, D. H. (2001). Body dysmorphic disorder: a review of conceptualizations, assessment, and treatment strategies. Clinical Psychology Review, 21, 949-970.

Duval, S., \& Wicklund, R. A. (1972). A theory of objective self-awareness. New York: Academic Press.

Grant, J. E., \& Phillips, K. A. (2005). Recognizing and treating body dysmorphic disorder. Annals of Clinical Psychiatry, 17, $205-210$.

Grocholewski, A., Heinrichs, N., \& Lingnau, A. (2007). Selektive Aufmerksamkeit im Gesichtsbereich bei Personen mit einem kosmetisch-medizinischen Behandlungswunsch. Zeitschrift für Klinische Psychologie und Psychotherapie, 36, 57-66.

Hofmann, S. G., \& Heinrichs, N. (2002). Disentangling self-descriptions and self-evaluations under conditions of high self-focused attention: effects of mirror exposure. Personality and Individual Differences, 32, 611-620. 
Jansen, A., Nederkoorn, C., \& Mulkens, S. (2005). Selective visual attention for ugly and beautiful body parts in eating disorders. Behaviour Research and Therapy, 43, 183-196.

Legenbauer, T., Kleinstauber, M., Muller, T., \& Stangier, U. (2008). Are individuals with an eating disorder less sensitive to aesthetic flaws than healthy controls? Journal of Psychosomatic Research, 65, 87-95.

Mulkens, S., Bögels, S. M., \& De Jong, P. J. (1999). Attentional focus and fear of blushing: a case study. Behavioural and Cognitive Psychotherapy, 27, 153-164.

Mulkens, S., Bögels, S. M., De Jong, P. J., \& Louwers, J. (2001). Fear of blushing: effects of task concentration training versus exposure in vivo on fear and physiology. Journal of Anxiety Disorders, 15, 413-432.

Nierenberg, A. A., Phillips, K. A., Peterson, T. J., Kelly, K. E., Alpert, J. E., Worthington, J. J., et al. (2002). Body dysmorphic disorder in outpatients with major depression. Journal of Affective Disorders, 169, 141-148.

Phillips, K. A. (1996). The broken mirror: Recognizing and treating body dysmorphic disorder. New York: Oxford University Press.

Phillips, K. A. (1999). Body dysmorphic disorder and depression: theoretical considerations and treatment strategies. Psychiatric Quarterly, 70, 313-331.

Phillips, K. A., \& Diaz, S. F. (1997). Gender differences in body dysmorphic disorder. The Journal of Nervous and Mental Disease, $185,570-577$.

Phillips, K. A., Kim, J. M., \& Hudson, J. I. (1995). Body image disturbance in body dysmorphic disorder and eating disorders: obsessions or delusions? Psychiatric Clinics of North America, 18, 317-334.

Rapee, R. M., \& Heimberg, R. G. (1997). A cognitive-behavioral model of anxiety in social phobia. Behaviour Research and Therapy, $35,741-756$

Rief, W., Buhlmann, U., Wilhelm, S., Borkenhagen, A., \& Brähler, E. (2006). The prevalence of body dysmorphic disorder: a population-based survey. Psychological Medicine, 36, 877-885.

Rosen, J. C. (1995). The nature of body dysmorphic disorder and treatment with cognitive behavior therapy. Cognitive and Behavioral Practice, 2, 143-166.

Veale, D. (2000). Outcome of cosmetic surgery and 'DIY' surgery in patients with body dysmorphic disorder. Psychiatric Bulletin, $24,218-221$.

Veale, D. (2004). Advances in a cognitive behavioural model of body dysmorphic disorder. Body Image, 1, 113-125.

Veale, D., Gournay, K., Dryden, W., Boocock, A., Shah, F., Willson, R., et al. (1996). Body dysmorphic disorder: a cognitive behavioural model and pilot randomised controlled trial. Behaviour Research and Therapy, 34, 717-729.

Veale, D., \& Riley, S. (2001). Mirror, mirror on the wall, who is the ugliest of them all? The psychopathology of mirror gazing in body dysmorphic disorder. Behaviour Research and Therapy, 39, 1381-1393.

Zou, J. B., Hudson, J. L., \& Rapee, R. M. (2007). The effect of attentional focus on social anxiety. Behaviour Research and Therapy, $45,2326-2333$. 